\title{
Association of giant retinal tear with iridofundal coloboma in a case of paediatric retinal detachment
}

\author{
Srikanta Kumar Padhy, ${ }^{1}$ Brijesh Takkar, ${ }^{2}$ Sohini Mandal, ${ }^{1}$ Suman Sahu ${ }^{1}$
}

${ }^{1}$ Department of Ophthalmology, Dr. Rajendra Prasad Centre for Ophthalmic Sciences, AllMS, Delhi, New Delhi, India ${ }^{2}$ Department of Ophthalmology, All India Institute of Medical Science, Bhopal, Madhya Pradesh, India

Correspondence to Dr Srikanta Kumar Padhy, srikantkumar.padhy19@gmail. com

Accepted 22 August 2018

\section{DESCRIPTION}

A 6-year-old boy presented with history of suddenonset painless diminution of vision oculus dexter (OD) since the last sixhours. The vision loss was preceded by a sudden shower of floaters. There was no history of recent or remote trauma, and no positive family history of ocular illness could be elicited from the parents. Visual acuity was perception of light with accurate projection of rays OD and 20/20 oculus sinister (OS). A typical and complete iris coloboma with keyhole pupil was noted OD. There was no sign of trauma in either eye. Intraocular pressures measured to $6 \mathrm{~mm} \mathrm{Hg}$ $\mathrm{OD}$ and $13 \mathrm{~mm} \mathrm{Hg}$ OS. Dilated fundus examination showed type II choroidal coloboma involving the macula (Ida Mann classification) with total rhegmatogenous retinal detachment OD. Peripheral examination revealed a giant retinal tear (GRT), extending almost five clock hours, with a posterior flap falling over the posterior pole (figure 1). OS was completely normal on examination. Sonography confirmed the posterior segment findings OD (figure 2), and the axial length was measured as $23.12 \mathrm{OD}$ and $23.17 \mathrm{~mm}$ OS.

Immediate pars plana vitrectomy with encircling band silicone oil tamponade was performed under general anaesthesia OD. During the surgery, perfluorocarbon liquid (PFCL) was used to flatten the rolled retina, followed by endo-laser photocoagulation of GRT and margins of the fundal coloboma, and lastly PFCL-silicone oil exchange. Routine postoperative care with prone position was advised. Retina was found to be attached and well lasered 20 days after surgery (figure 3 ), with a best-corrected vision of 20/200 and normal ocular pressure.

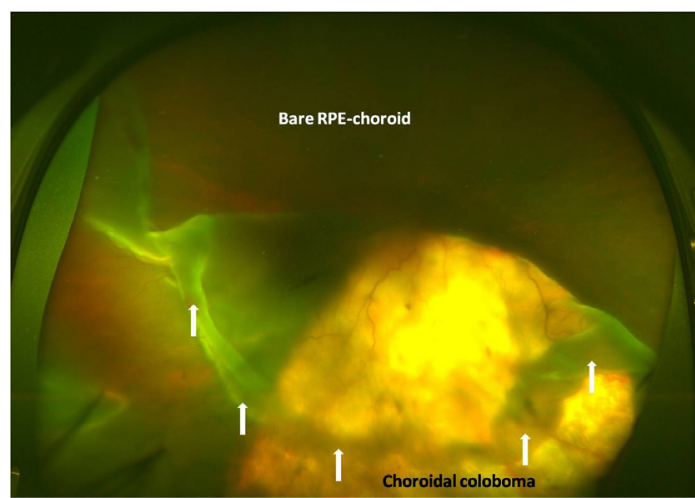

Figure 1 Ultrawide field image OD showing the giant retinal tear, bare retinal pigment epithelium (RPE)choroid and the choroidal coloboma. The posterior flap of the tear has fallen over the colobomatous area (white arrows).

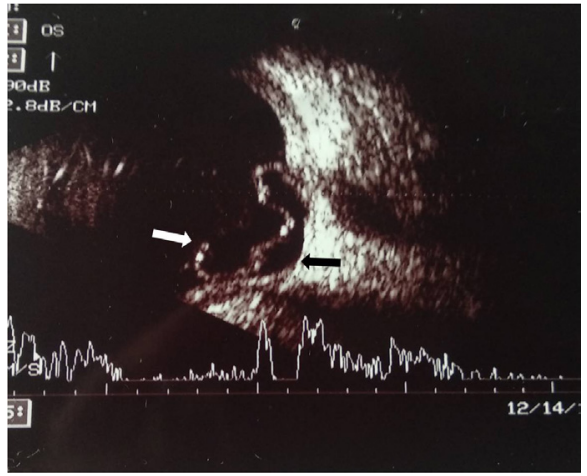

Figure 2 Ultrasound image OD showing the giant retinal tear (white arrow). The choroidal coloboma can be seen as an excavation (black arrow).

GRTs are more known to occur in patients with high myopia, Marfan syndrome, Stickler syndrome, aniridia and following trauma. Its pathogenesis involves an abnormal cortical vitreous and sudden central gel contraction that leads to circumferential 'ripping' of the retina. Iridofundal coloboma (IFC) is a congenital anomaly occurring due to incomplete closure of the embryonic fissure during fetal development. About $40 \%$ of such eyes develop retinal detachment in lifetime. In most cases, breaks are located in the base of intercalary membrane or at the edge of the coloboma itself. To our knowledge, an association between IFC and GRT has not been described. This is not surprising as one does not expect inner retinal anomalies or vitreous anomalies with choroidal coloboma as the embryonic defect mainly involves the outer layer of the optic cup. Although colobomas may be associated with other retinal anomalies, ${ }^{1}$ gross vitreoretinopathy is a rare association, and hence GRTs are unlikely. Myopia

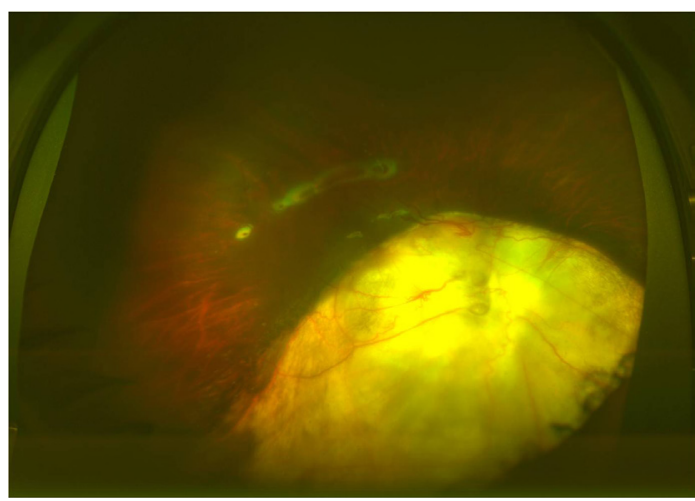

Figure 3 Ultrawide field image OD 3rd week following surgery showing attached retina with oil filled eye. 
is a common factor between the two, but the eye was normal sized in this case. In 1968, Hovland et al described eight cases of lens coloboma in association with GRT and hypothesised the simultaneous occurrence to be a result of persistent mesoderm between developing optic cup and lens/zonules causing traction. ${ }^{2}$

Both these conditions pose an immense surgical challenge while alone, and their simultaneous occurrence is likely to effect surgical outcomes. In particular, use of injectable surgical adjuncts in cases of choroidal coloboma is questionable due to risk of subretinal migration because of an unrelieved vitreous traction at the edge of the coloboma which may have breaks too. ${ }^{3}$ On the other hand, PFCLs are central to surgical success

\section{Learning points}

- Giant retinal tears may be rarely associated with ocular colobomata.

- This association may be coincidental or a part of broader dysgenesis.

- Such cases are a surgical challenge, and management should be done as soon as possible. in case of GRT for multiple reasons. Fortunately, in our case, no subretinal migration of PFCL was seen. Other postoperative complications include a higher theoretical risk of proliferative vitreoretinopathy, that is, an accompaniment of both GRT and coloboma, for which we are carefully following up this case.

Contributors SKP and BT: concept and design. SM: concept and acquisition of data. SS: concept.

Funding The authors have not declared a specific grant for this research from any funding agency in the public, commercial or not-for-profit sectors.

Competing interests None declared.

Patient consent Parental/guardian consent obtained.

Provenance and peer review Not commissioned; externally peer reviewed.

\section{REFERENCES}

1 Khokhar S, Takkar B, Pillay G, et al. Three Cases of Associated Persistent Fetal Vasculature and Ocular Coloboma: Posterior Segment Dysgenesis. J Pediatr Ophthalmol Strabismus 2017;54:e77.

2 Hovland KR, Schepens CL, Freeman HM. Developmental giant retinal tears associated with lens coloboma. Arch Ophthalmol 1968;80:325-31.

3 Wadhwa N, Venkatesh P, Sampangi R, et al. Rhegmatogenous retinal detachments in children in India: clinical characteristics, risk factors, and surgical outcomes. J Aapos 2008;12:551-4.

Copyright 2018 BMJ Publishing Group. All rights reserved. For permission to reuse any of this content visit

http://group.bmj.com/group/rights-licensing/permissions.

BMJ Case Report Fellows may re-use this article for personal use and teaching without any further permission.

Become a Fellow of BMJ Case Reports today and you can:

- Submit as many cases as you like

- Enjoy fast sympathetic peer review and rapid publication of accepted articles

- Access all the published articles

- Re-use any of the published material for personal use and teaching without further permission

For information on Institutional Fellowships contact consortiasales@bmjgroup.com

Visit casereports.bmj.com for more articles like this and to become a Fellow 